BEDECARRATZ, Francisco. "La indeterminación del criminal compliance y el principio de legalidad".

Polít. crim. Vol. 13, № 25 (Julio 2018) Art. 6, pp. 208-232.

[http://www.politicacriminal.cl/Vol_13/n_25/Vol13N25A6.pdf]

\title{
La indeterminación del criminal compliance y el principio de legalidad
}

\section{The indetermination of the criminal compliance and the principle of legality}

\author{
Prof. Dr. iur. Francisco Javier Bedecarratz Scholz* \\ Universidad Autónoma de Chile, Santiago, Chile \\ francisco.bedecarratz@uautonoma.cl
}

\section{Resumen}

El presente trabajo realiza un análisis crítico de la recepción de los modelos de criminal compliance en la ley penal. En las siguientes líneas, el autor postula que el modelo impuesto por la Ley $\mathrm{N}^{\circ} 20.393$ adolece de graves problemas de determinación, que afectan el principio de legalidad penal en su característica de lex certa. La creación de sistemas de autorregulación forzada con obligaciones de contenido incompleto o equívoco, no puede lícitamente sustentar un reproche penal para el caso que se dé su incumplimiento. Un análisis de otros modelos nacionales y de Derecho comparado indica que sí existen modelos de criminal compliance en concordancia con el principio de legalidad. En conclusión, se propone especificar los deberes de autorregulación a través de normativa infra-legal dictada por organismos sectoriales, respetando los requisitos de constitucionalidad establecidos para las leyes penales en blanco.

\section{Palabras clave}

Compliance, autorregulación, gobierno corporativo, modelos de prevención, lex certa.

\begin{abstract}
This paper is a critical analysis of the statutory regulation of criminal compliance models in criminal law. In the following pages, the author maintains that the model imposed in Act No. 20.393 has serious determination problems, which affect the principle of legality in its attribute of lex certa. The creation of an enforced self-regulation model with unclear or incomplete obligations, cannot justify the imposition of criminal sanctions in the case of their infraction. An analysis of other criminal compliance models in Chile and in other jurisdictions shows, that there are alternative regulatory techniques that preserve the legality principle. The author proposes the specification of the criminal compliance mandates through infra-legal provisions dictated by sectorial regulators, while respecting the constitutional requisites for incomplete penal statutes.
\end{abstract}

\section{Key words}

\footnotetext{
* Abogado. Licenciado en Ciencias Jurídicas y Sociales por la Universidad Autónoma de Chile. Magister Legum y Doctor iuris por la Philipps-Universität Marburg, Alemania. Profesor de Derecho penal de la Universidad Autónoma de Chile.
} 
Polit. crim. Vol. 13, № 25 (Julio 2018) Art. 6, pp. 208-232.

[http://www.politicacriminal.cl/Vol_13/n_25/Vol13N25A6.pdf]

Compliance, self-regulation, corporate governance, prevention models, lex certa.

\section{Introducción}

La forma de organización de las empresas ha sido desde antiguo considerada una materia más propia de las ciencias empresariales que del Derecho Penal. Sin embargo, el aumento en la intensidad y complejidad de los delitos económicos, sumado a la introducción de la responsabilidad penal de las personas jurídicas, ha hecho que la forma como se organizan las asociaciones adquiera una creciente relevancia en materia penal. Esta evolución ha impulsado al Estado a imponer modelos de autorregulación a las asociaciones, cuya principal función es impedir o al menos dificultar la comisión de hechos punibles perpetrados en su seno.

A través de su consagración legal en normas penales, el Estado le ordena a las asociaciones implementar este tipo de medidas en sus estructuras y al mismo tiempo les delega su función tradicional de investigación de hechos punibles a nivel de la organización. En caso de incumplirse esta obligación, la entidad queda expuesta a consecuencias penales derivadas de los hechos que sus integrantes hayan cometido en el ejercicio de sus funciones, la cual puede conllevar hasta la cancelación de su personalidad jurídica.

Esta vinculación que ha hecho el legislador entre omisión del deber de autorregulación por una parte y sanción penal por la otra, hace necesario que los modelos de autorregulación impuestos por la ley cumplan con los requisitos que la ley penal establece para la aplicación de las penas. En concreto, se plantea el problema de que el modelo de autorregulación forzada incorporado por la Ley $\mathrm{N}^{\circ} 20.393$, impone medidas que no cuentan con la precisión normativa exigida por el ordenamiento penal. Este artículo pretende arrojar nueva luz al problema de indeterminación desde la perspectiva del principio de legalidad, para finalmente elaborar una propuesta en base a otros modelos de criminal compliance regulados en el Derecho interno y comparado.

\section{El "criminal compliance"}

Los programas de compliance son sistemas organizativos que incluyen principios, reglas, procedimientos e instrumentos orientados a asegurar el cumplimiento de la legalidad en el desarrollo de las actividades de una organización. ${ }^{1}$ El criminal compliance comprende todas las medidas normativas, institucionales y técnicas de una organización dirigidas a sus miembros, a sus contrapartes contractuales, al Estado o al público en general, que sean objetivamente necesarias ex ante o penalmente admisibles ex post para: a) disminuir el riesgo de que la organización o sus miembros perpetren un delito económico organizacional contrario a Derecho nacional o extranjero o generen sospecha de la comisión del mismo (aspecto preventivo-material); b) mejorar las posibilidades de influenciar positivamente un

\footnotetext{
${ }^{1}$ NEIRA PENA, Ana María, "La efectividad de los criminal compliance programs como objeto de prueba en el proceso penal", Polít. Crim., Vol. 11, N 22 (2016), pp. 467-520, p. 469. Cfr. además BOCK, Dennis, "Compliance y deberes de vigilancia en la empresa", en: KUHLEN, Lothar, MONTIEL, Juan Pablo, ORTÍZ DE URBINA GIMENO, Íñigo (Eds.), Compliance y teoría del Derecho Penal, Madrid: Marcial Pons, 2013, pp. 107-124, pp. $107 \mathrm{y}$ s.
} 


\section{BEDECARRATZ, Francisco. "La indeterminación del criminal compliance y el principio de legalidad".}

proceso sancionatorio en consenso con los órganos de persecución penal, para así finalmente preservar el valor de la empresa (aspecto procesual-represivo), y; c) Evitar daños de reputación para la empresa que puedan surgir producto de la no detección a tiempo de un ilícito al interior de la organización (aspecto económico). ${ }^{2}$

El problema jurídico de la falta de determinación del criminal compliance se plantea desde la valoración de sus funciones que realiza el Estado por un lado y las personas jurídicas por el otro. Desde la perspectiva del Estado, su principal función es ser una medida preventiva contra la comisión de hechos punibles (aspecto preventivo-material). El Estado delega funciones de investigación de hechos punibles empresariales a la propia persona jurídica, ${ }^{3}$ lo cual tiene como fundamento razones prácticas. Entre estas razones está que las investigaciones internas se realizan a costa de la persona jurídica, lo cual va en directo beneficio financiero del Estado. ${ }^{4} \mathrm{Se}$ postula además que la implementación de procedimientos preventivos especiales hecha por el propio generador del riesgo, en este caso las personas jurídicas, será siempre más efectiva que la regulación estatal. ${ }^{5}$ La corporación posee información acerca de su estructura organizacional, personal, modelo de negocios y en general know-how interno que no se encuentra a disposición del Estado. ${ }^{6}$ Además, la empresa no se encuentra limitada por principios procesales tales como el nemo-tenetur, puesto que el empleado no podría acogerse al derecho a guardar silencio en el marco de investigaciones internas, ${ }^{7}$ lo cual constituye una gran ventaja en relación con investigaciones realizadas por el Estado. ${ }^{8}$

\footnotetext{
${ }^{2}$ ROTSCH, Thomas, "Compliance und Strafrecht - Fragen, Bedeutung, Perspektiven. Vorbemerkungen zu einer Theorie der sog. "Criminal Compliance”", ZStW, No 125 (2013), pp. 481-498, p. 494.

${ }^{3}$ KUHLEN, Lothar, "Compliance y Derecho Penal en Alemania", en: MIR PUIG, Santiago, CORCOY BIDASOLO, Mirentxu, GÓMEZ MARTÍN, Víctor (dirs.), Responsabilidad de la Empresa y Compliance. Programas de prevención, detección y reacción penal, Madrid: Edisofer S. L., 2014, pp. 89-125, pp. 103 y ss. NIETO MARTÍN, Adán, La Responsabilidad Penal de las Personas Jurídicas: un Modelo Legislativo, Madrid: Iustel, 2008, pp. 59 y ss.

${ }^{4}$ Por ejemplo, en el caso de corrupción que afectó a Siemens entre los años 2006 a 2008, la investigación interna realizada por el estudio jurídico Debevoise \& Plimpton LL.P. y que empleó los servicios de la sociedad auditora Deloitte, tuvo un costo aproximado de mil millones de euros. Los resultados penalmente relevantes fueron puestos a disposición de las autoridades de persecución penal. KUHLEN, "Compliance y Derecho Penal en Alemania", cit. nota n 3, p. 108.

5 COLLADO GONZÁLEZ, Rafael, Empresas criminales. Un análisis de los modelos legales de responsabilidad penal de las personas jurídicas implementados en Chile y en España, Santiago: Legal Publishing Chile, 2013, pp. 19 y s.

${ }^{6}$ PIÑA ROCHEFORT, Juan Ignacio, Modelos de prevención de delitos en la empresa, Santiago: Abeledo Perrot, 2012, p. 3 y p. 36.

${ }^{7}$ En relación con las personas jurídicas como titulares de este derecho, vid. HERNÁNDEZ BASUALTO, Héctor, “¿Derecho de las personas jurídicas a no auto-incriminarse?”, Revista de Derecho de la Pontificia Universidad Católica de Valparaíso, $\mathrm{N}^{\circ} 44$ (2015), pp. 217-263; lo mismo desde la perspectiva germana en BÖSE, Martin, "Strafbarkeit juristischer Personen - Selbstverständlichkeit oder Paradigmenwechsel im Strafrecht", ZStW, No 126 (2014), pp. 132-165, pp. 162 y ss.; BECKEMPER, Katharina, "Nemo teneturGrundsatz im Steuerstrafrecht. Verwertbarkeit einer gescheiterten Selbstanzeige?", ZIS, No 5 (2012), pp. 221227, pp. 221 y ss.; una exposición desde la perspectiva suiza en GETH, Christopher, "Selbstbelastungsfreiheit im Unternehmensstrafrecht - Konflikt zwischen Moderne und Tradition aus Schweizer Perspektive", ZStW, No 126 (2014), pp. 105-121, pp. 105 y ss.

${ }^{8}$ ROTSCH, "Compliance und Strafrecht", cit. nota n ${ }^{\circ} 2$, p. 488.
} 
Desde la perspectiva de la persona jurídica en cambio, el objetivo de prevención de delitos empresariales depende directamente de la consagración de los modelos en el ordenamiento jurídico respectivo, esto es, si la implementación de programas de compliance al momento de comisión de un delito constituye una eximente o atenuante penal en beneficio de la persona jurídica (aspecto procesual-represivo). En dicho caso, la organización tendrá mayor interés en introducir estos programas con el objeto de evitar o morigerar una sanción penal. ${ }^{9}$ Pero el cumplimiento de los mandatos específicos impuestos por los modelos de autorregulación forzada, depende directamente del nivel de determinación con el cual se regulen en la ley penal.

\section{La indeterminación de los modelos de criminal compliance}

La consagración de modelos de criminal compliance en la ley va comúnmente acompañada de la enumeración de los requisitos mínimos de las medidas a implementar, para que luego la persona jurídica, según su contexto particular, concretice y dé forma final a los programas. El principio fundamental radica en que no se describan todos los aspectos del modelo de autorregulación, pues una propuesta legislativa específica no sería adaptable a los innumerables tipos de actividades económicas que, a su vez, generan riesgos penales específicos. ${ }^{10}$ Una norma estática carecería de la capacidad de adaptación necesaria en un entorno eminentemente cambiante, todo lo cual redundaría, por lo tanto, en su inefectividad. ${ }^{11}$

Sin embargo, la indeterminación de los programas de compliance, considerada como necesaria para garantizar su efectividad para la prevención de riesgos penales, resulta difícilmente conciliable con el principio de legalidad penal. En específico, se infringe el principio de ley cierta o nullum crimen, nulla poena sine lege certa. ${ }^{12}$ Según este principio, se exige que los tipos penales estén estructurados de la forma más precisa posible, determinando al máximo todos sus elementos, para así proporcionar a las personas claridad sobre qué prohíbe y qué permite el ordenamiento penal. Este principio no constituye una simple norma programática, sino que es parte esencial de la función de garantía del Derecho Penal y confiere a todas las personas protección frente al ejercicio arbitrario del ius puniendi estatal. Es además un requisito fundamental del efecto útil del Derecho Penal, pues las personas pueden adecuar su comportamiento a la norma punitiva, sólo en la medida que el contenido de esta sea suficientemente claro y determinado.

\footnotetext{
${ }^{9}$ En otros casos sólo queda como incentivo para la creación de programas de compliance la prevención de daños de reputación para la empresa a causa de la comisión de hechos punibles en su seno (aspecto económico). ROTSCH, "Compliance und Strafrecht", cit. nota n 2, p. 487.

${ }^{10}$ Por ejemplo, los riesgos de una organización que ejerce actividades bancarias son totalmente distintos a los de una organización que se dedica a celebrar contratos de concesiones con el Estado para realizar obras públicas. En la primera, el riesgo principal es el de fraudes y de lavado de dinero, mientras que en la segunda lo es el de cohecho. Otros ejemplos en PIÑA ROCHEFORT, Modelos de prevención, cit. nota n ${ }^{\circ}$ 6, pp. 3 y s.

${ }^{11}$ ARTAZA VARELA, Osvaldo, "Sistemas de prevención de delitos o programas de cumplimiento. Breve descripción de las reglas técnicas de gestión del riesgo empresarial y su utilidad en sede jurídico penal", Polít. Crim., Vol. 8, $\mathrm{N}^{\circ} 16$ (2013), pp. 544-573, pp. 549 y s.

${ }^{12}$ Cfr. CURY URZÚA, Enrique, Derecho Penal, Parte General, 10 ${ }^{a}$ edición, Santiago: Ediciones Universidad Católica de Chile, 2011, pp. 167 y s., quien lo considera implícito en el principio de prohibición de la analogía. Aquí se seguirá un modelo diferenciado, vid. por todos a ROXIN, Claus, Strafrecht Allgemeiner Teil, T. 1, $4^{a}$ edición, München: C.H. Beck, 2006, pp. 138 y ss., pp.172 y ss.
} 
BEDECARRATZ, Francisco. "La indeterminación del criminal compliance y el principio de legalidad".

Al establecerse un requisito de imputación ${ }^{13}$ con contornos difusos, como sucede con la recepción legal de programas de criminal compliance, se infringe el principio de determinación penal. Ello, pues los modelos establecen mandatos generales que no fijan con precisión la obligación cuyo incumplimiento genera la respuesta punitiva. La imposición de obligaciones (implementación de modelos de prevención de delitos) de contenido equívoco (contenido específico y forma en que debe implementarse el modelo) crea inseguridad jurídica tanto para organizaciones como para los individuos que las integran. Este fenómeno permite además al Estado realizar interpretaciones más amplias o restrictivas según sea su conveniencia, transformándose en arbitrario el ejercicio del poder punitivo del Estado.

Debido a lo anterior, se abre la posibilidad de que los jueces desestimen los programas de compliance y les nieguen valor como atenuantes o eximentes de responsabilidad penal, aun cuando el programa contemple todos los elementos prescritos por la ley, basados en que el modelo es insuficiente para cumplir alguno de los requisitos legales o que falta al interior de la organización una voluntad real de implementar efectivamente el modelo.

El ordenamiento jurídico chileno exhibe dos grandes ejemplos en los cuales se establecen deberes de criminal compliance para las personas jurídicas, y que grafican adecuadamente el problema de indeterminación. Estos son el art. $4^{\circ}$ de la Ley $\mathrm{N}^{\circ} 20.393$ (epígrafe 2.1) y los arts. $3^{\circ}$ a $7^{\circ}$ de la Ley $\mathrm{N}^{\circ} 19.913$ (epígrafe 2.2 ).

\subsection{La indeterminación del modelo impuesto a las personas jurídicas}

La Ley N²0.393 que "Establece la Responsabilidad Penal de las Personas Jurídicas en los Delitos de Lavado de Activos, Financiamiento del Terrorismo y Delitos de Cohecho que Indica", establece en su art. $3^{\circ}$ in. $1^{\circ}$ un modelo de imputación, enumerando una serie de requisitos objetivos y subjetivos para atribuir un determinado hecho punible a la persona jurídica. ${ }^{14}$ Dentro de estos requisitos se establece el defecto de organización en la persona jurídica. ${ }^{15}$ El delito deber haber sido cometido como consecuencia del incumplimiento, por parte de la persona jurídica, de los deberes de dirección y supervisión. ${ }^{16}$

\footnotetext{
${ }^{13}$ En cuanto a la naturaleza dogmática de los modelos de prevención de delitos, la mayoría de los autores los consideran como parte del injusto central de la organización. En este sentido PIÑA ROCHEFORT, Modelos de prevención, cit. nota ${ }^{\circ}$ 6, p. 7; COLLADO GONZÁLEZ, Empresas criminales, cit. nota n ${ }^{\circ} 5$, pp. 81 y s. Cfr. NIETO MARTÍN, Adán, "Problemas fundamentales del cumplimiento normativo en el Derecho penal", en: KUHLEN, Lothar, MONTIEL, Juan Pablo, ORTÍZ DE URBINA GIMENO, Íñigo (Eds.), Compliance y teoría del Derecho Penal, Madrid: Marcial Pons, 2013, pp. 21-50, pp. 38 y s. Un análisis de la jurisprudencia española reciente por DEL ROSAL BLASCO, Bernardo, "Sobre los elementos estructurales de la responsabilidad penal de las personas jurídicas: reflexiones sobre las SSTS 154/2016 y 221/2016 y sobre la Circular núm. 1/2016 de la Fiscalía General del Estado”, Diario La Ley, N 8732 (2016), pp. 1-13, pp. 1 y ss. Panorama de la discusión en NEIRA PENA, "La efectividad de los criminal compliance programs", cit. nota n 1, pp. 500 y ss.

${ }^{14}$ Análisis de los requisitos en HERNÁNDEZ BASUALTO, Héctor, "La introducción de la responsabilidad penal de las personas jurídicas en Chile”, Polít. Crim., Vol. 5, N 9 (2010), pp. 207-236, pp. 220 y s.

15 Sobre la naturaleza de este elemento como requisito típico vid. COLLADO GONZÁLEZ, Empresas criminales, cit. nota $\mathrm{n}^{\circ} 13$, pp. 166 y ss.

${ }^{16}$ Una crítica de este requisito desde una perspectiva individualista expone VAN WEEZEL, Alex, "Contra la responsabilidad penal de las personas jurídicas”, Polít. Crim., Vol. 5, Nº (2010), pp. 114-142, p. 138.
} 
Polit. crim. Vol. 13, № 25 (Julio 2018) Art. 6, pp. 208-232.

[http://www.politicacriminal.cl/Vol_13/n_25/Vol13N25A6.pdf]

$\mathrm{El}$ art. $3^{\circ}$ in. $1^{\circ}$ in fine Ley $\mathrm{N}^{\circ} 20.393$ establece que la persona jurídica no será penalmente responsable por los hechos de sus agentes en caso de que esta cumpla con sus deberes de dirección y supervisión. En virtud de esta norma, la persona jurídica se transforma en un verdadero garante en relación con los hechos cometidos por sus miembros y se encuentra obligada a supervisar a sus agentes. Es respecto a este último criterio de imputación que se establece un modelo de compliance que genera importantes efectos para la responsabilidad de la persona jurídica.

El precepto requiere la adopción e implementación, con anterioridad a la comisión del delito, de "modelos de organización, administración y supervisión para prevenir delitos como el cometido", especificándose luego en el art. $4^{\circ}$ Ley $\mathrm{N}^{\circ} 20.393$ los requisitos mínimos del modelo de prevención de delitos para lograr la exclusión de responsabilidad de la persona jurídica.

Las dos primeras medidas organizativas están enumeradas en los numerales 1 y 2 del art. $4^{\circ}$ Ley $\mathrm{N}^{\circ}$ 20.393. El legislador busca lograr una disminución del riesgo de comisión de delitos a través de medidas organizativas. Se ordena la creación de un organismo al interior de la empresa encargado de las tareas de prevención y dotado de los medios necesarios al efecto, disponiendo además la separación entre organismo controlador y la dirección de la persona jurídica $\left(\mathrm{N}^{\circ} 1\right.$ lit. b)). Para garantizar la implementación de medidas preventivas al interior de la organización, se obliga a las personas jurídicas a establecer canales de comunicación directos entre el encargado de prevención y la dirección de la persona jurídica $\left(\mathrm{N}^{\circ} 2\right.$ lit. b)).

Por su parte, el art. $4^{\circ} \mathrm{N}^{\circ} 3$ Ley $\mathrm{N}^{\circ} 20.393$ consagra la obligación para la persona jurídica de gestión y control de riesgos penales, disponiendo la creación de un sistema de prevención destinado a reducir la comisión de delitos al interior de la organización. La norma pasa a enumerar una serie de requisitos mínimos del sistema. ${ }^{17}$

La ley establece un sistema que consta de cuatro fases: la identificación y prevención de riesgos, junto a la detección y sanción de contravenciones. ${ }^{18}$ Sin embargo, el texto legal no realiza mayor precisión en cuanto al contenido de estas obligaciones. No establece cómo debe realizarse el análisis de riesgo contemplado en art. $4^{\circ} \mathrm{N}^{\circ} 3^{\circ}$ lit. a) Ley $\mathrm{N}^{\circ} 20.393$, o si debe hacerse una estimación de la probabilidad de ocurrencia del riesgo y del potencial daño en caso de que el riesgo se materialice. No enumera ni siquiera a título ejemplar las medidas

17 “3) Establecimiento de un sistema de prevención de los delitos.

El encargado de prevención, en conjunto con la Administración de la Persona Jurídica, deberá establecer un sistema de prevención de los delitos para la persona jurídica, que deberá contemplar a lo menos lo siguiente:

a) La identificación de las actividades o procesos de la entidad, sean habituales o esporádicos, en cuyo contexto se genere o incremente el riesgo de comisión de los delitos señalados en el artículo $1^{\circ}$.

b) El establecimiento de protocolos, reglas y procedimientos específicos que permitan a las personas que intervengan en las actividades o procesos indicados en el literal anterior, programar y ejecutar sus tareas o labores de una manera que prevenga la comisión de los mencionados delitos.

c) La identificación de los procedimientos de administración y auditoría de los recursos financieros que permitan a la entidad prevenir su utilización en los delitos señalados.

d) La existencia de sanciones administrativas internas, así como de procedimientos de denuncia o persecución de responsabilidades pecuniarias en contra de las personas que incumplan el sistema de prevención de delitos."

${ }^{18}$ Compárese con las etapas enumeradas en NEIRA PENA, "La efectividad de los criminal compliance programs", cit. nota $\mathrm{n}^{\circ} 1$, pp. 471 y ss. 


\section{BEDECARRATZ, Francisco. "La indeterminación del criminal compliance y el principio de legalidad".}

preventivas de carácter general que puede implementar la persona jurídica para disminuir el riesgo de comisión de delitos al interior de ella. Ello implica que los requisitos generales que establece la norma no son de ninguna manera autosuficientes. Deben ser complementados por otros criterios y principios fijados por vía extra-legal. ${ }^{19}$

Por otra parte, cabe destacar que la Ley $\mathrm{N}^{\circ} 20.393$ no exige la instauración del modelo descrito en su art. $4^{\circ}$ como única forma de cumplir con los deberes de dirección y supervisión de la persona jurídica. Es posible, por ejemplo, que la persona jurídica adopte otro tipo de medidas que cumplan con deberes de dirección y establezca una adecuada supervisión de sus directivos y empleados subalternos, lo cual puede ser considerado como cumplimiento de sus deberes. ${ }^{20}$ En este caso no operaría la presunción simplemente legal del art. $3^{\circ}$ in. $3^{\circ}$, de que la persona jurídica ha cumplido con sus deberes de dirección y supervisión, pues su efecto liberatorio está supeditado a la adopción de un modelo con las características del art. $4^{\circ}$. Sin embargo, se podría lograr la absolución de la persona jurídica acreditando el cumplimiento de los deberes dirección y supervisión del art. $3^{\circ}$ in. $1^{\circ}$, parte final, en virtud de las reglas generales.

En caso de los programas innominados, el problema de indeterminación se agrava en forma exponencial. Si bien es cierto que todo programa de criminal compliance debe en la práctica ser un medio adecuado para impedir la comisión de hechos punibles, ${ }^{21}$ no es menos cierto que existe una total incertidumbre respecto al contenido y a las características de estos modelos atípicos. ${ }^{22}$ Resta por lo tanto determinar las características necesarias para lograr una equivalencia material entre los modelos innominados y aquel propuesto en el art. $4^{\circ}$ Ley $\mathrm{N}^{\circ} 20.393 .^{23}$

El verdadero desafío consiste en determinar los elementos mínimos que impliquen un cumplimiento de los deberes de dirección y supervisión. La Ley $\mathrm{N}^{\circ} 20.393$ determina en su art. $4^{\circ}$ los requisitos indispensables del modelo de organización, administración y supervisión, pero sin especificar en qué consisten los "deberes de dirección y supervisión” que debe cumplir la empresa según el art. $3^{\circ}$ in. $1^{\circ}$ parte final. La ley incurre en una paradoja en la cual define la excepción, sin antes haber definido la norma general.

Considerando que el incumplimiento de los deberes de dirección y supervisión es un criterio material de imputación de responsabilidad penal que debe ser acreditado por el organismo

\footnotetext{
${ }^{19}$ PIÑA ROCHEFORT, Modelos de Prevención, cit. nota n 6, pp. 9 y s. ARTAZA VARELA, "Sistemas de prevención", cit. nota n ${ }^{\circ} 11$, pp. 547 y ss., pp. 568 y ss.

${ }^{20}$ Ya advertido por HERNÁNDEZ BASUALTO, "La introducción de la responsabilidad penal”, cit. nota n ${ }^{\circ} 14$, pp. 225 y s.; refirmado por PIÑA ROCHEFORT, Modelos de Prevención, cit. nota n ${ }^{\circ}$ 6, p. 8.

${ }^{21}$ Contando por ejemplo con un organismo encargado de prevención, análisis de riesgo, medidas normativas, institucionales o técnicas de mitigación y contención del riesgo identificado, junto a los correspondientes controles y sistema sancionatorio, debiendo el programa además ser actualizado constantemente y de acuerdo a los cambios en el perfil de negocio y actividades de la persona jurídica.

${ }^{22}$ PIÑA ROCHEFORT, Modelos de Prevención, cit. nota $n^{\circ}$ 6, p. 8, en especial nota $n^{\circ} 22$ en el texto. BEDECARRATZ SCHOLZ, Francisco Javier, Rechtsvergleichende Studien zur Strafbarkeit juristischer Personen. Eine Untersuchung ihrer Strafzurechnungsmerkmale in den Rechtsordnungen von Chile, Deutschland, England, Frankreich, Spanien und den Vereinigten Staaten, Baden-Baden: Nomos, 2016, p. 204. ${ }^{23}$ HERNÁNDEZ BASUALTO, Héctor, "Desafíos de la ley de responsabilidad penal de las personas jurídicas", Revista de Estudios de la Justicia, No 16 (2012), pp. 75-98, p. 84.
} 
Polit. crim. Vol. 13, № 25 (Julio 2018) Art. 6, pp. 208-232.

[http://www.politicacriminal.cl/Vol_13/n_25/Vol13N25A6.pdf]

acusador, ${ }^{24}$ y que la ley no entrega ni siquiera los requisitos mínimos sobre qué se entiende por estos deberes en forma abstracta, el art. $3^{\circ}$ in. $1^{\circ}$ también afecta el principio de legalidad penal establecido en el art. $19 \mathrm{~N}^{\mathrm{o}} 3$ in. final de la Constitución. Al no definir en qué consisten los deberes de dirección y supervisión, tampoco queda claro normativamente en qué consiste el incumplimiento de dichos deberes, quedando indeterminada la conducta a sancionar. Se entrega así la precisión de la hipótesis de hecho (en nada menos que un requisito fundamental del modelo de imputación) al propio juez que debe aplicarla. El establecimiento de un caso concreto y específico en el cual dichos deberes se "considerarán cumplidos" no basta al efecto, pues resta por definir la norma abstracta y general sobre en qué consisten dichos deberes.

\subsection{Compliance y lavado de activos}

La Ley $\mathrm{N}^{\circ} 19.913$ del 18 de diciembre de 2003 establece en sus arts. $3^{\circ}$ a $7^{\circ}$ diversos deberes de organización y de colaboración que tienen por objeto impedir el aprovechamiento del sistema financiero y de otros sectores de la actividad comercial para la comisión del delito de lavado de activos. ${ }^{25}$

Los sujetos obligados a cumplir con estos deberes de organización y colaboración son las personas naturales y jurídicas enumeradas en el art. $3^{\circ}$ in. $1^{\circ}$ Ley $\mathrm{N}^{\circ} 19.913$ (en adelante: "sujetos obligados"). El catálogo es extenso, habiendo sido modificado constantemente desde la dictación de la norma, la última vez mediante la Ley $\mathrm{N}^{\circ} 20.950$ del 29 de octubre de 2016. La lista incluye entre otros a bancos y demás instituciones del sistema financiero, notarios, conservadores, administradoras de fondos de pensiones y sociedades deportivas.

La Ley $\mathrm{N}^{\circ} 19.913$ establece en primer lugar el deber de informar sobre las operaciones sospechosas de lavado de activos (definidas en primer lugar en su art. $3^{\circ}$ in. $\left.2^{\circ}\right)^{26}$ a la Unidad de Análisis Financiero (en adelante: "UAF"), incluyendo información sobre las características individuales de la operación y los sujetos involucrados. Los sujetos obligados tienen además el deber de remitir, a petición de la UAF y dentro del plazo fijado por ella, las informaciones complementarias necesarias o conducentes para desarrollar o completar el análisis de la operación sospechosa, o bien para intercambiarla con organismos internacionales similares, todo ello según el art. $2^{\circ}$ lit. b) y g) de la Ley $\mathrm{N}^{\circ} 19.913$.

El segundo deber para los sujetos obligados consiste en designar un funcionario responsable de relacionarse con la UAF, denominado "Oficial de Prevención de Lavado de Activos" u

\footnotetext{
${ }^{24}$ Así ha sido establecido expresamente por el Ministerio Público de Chile en el Oficio FN No 440/2010, p. 7 , y advertido por VAN WEEZEL, "Contra la Responsabilidad", cit. nota n ${ }^{\circ} 16$, p. 138 y s. NEIRA PENA, "La efectividad de los criminal compliance programs", cit. nota $\mathrm{n}^{\circ} 1$, p. 476.

${ }^{25}$ En relación con el sistema de prevención dispuesto por la Ley $\mathrm{N}^{\circ} 19.913$ vid. TOSO MILOS, Ángela, "Blanqueo de capitales su prevención en el ordenamiento jurídico chileno", Revista Chilena de Derecho, Vol. $35 \mathrm{~N}^{\circ} 3$ (2008), pp. 405-437, pp. 413 y ss.

${ }^{26} \mathrm{Si}$ bien es cierto que existe una definición legal de lo que se entiende por "operación sospechosa" en el art. $3^{\circ}$ in. $2^{\circ}$ Ley $\mathrm{N}^{\circ} 19.913$, es finalmente la UAF la cual define y comunica mediante circulares a los sujetos obligados los actos o situaciones especiales que son indiciarias de operaciones sospechosas, siendo la normativa marco para ello el art. $3^{\circ}$ in. $3^{\circ}$ Ley $\mathrm{N}^{\circ} 19.913$.
} 
BEDECARRATZ, Francisco. "La indeterminación del criminal compliance y el principio de legalidad".

“Oficial de Compliance", quien tendrá a su cargo la comunicación con la UAF acerca de las operaciones sospechosas.

La tercera obligación para los sujetos enumerados en el art. $3^{\circ}$ in. $1^{\circ}$ es "mantener registros especiales por el plazo mínimo de cinco años, e informar a la Unidad de Análisis Financiero cuando ésta lo requiera, de toda operación en efectivo superior a diez mil dólares de los Estados Unidos de América o su equivalente [...]" (art. $5^{\circ}$ ).

La cuarta obligación impuesta a los sujetos obligados es una de no hacer, específicamente de guardar secreto sobre los traspasos de información desde y hacia la UAF, con el objeto de no frustrar las investigaciones sobre hechos constitutivos de lavado de activos que pudieren iniciarse con ocasión del traspaso (art. $6^{\circ}$ ).

Cabe destacar que el art. $3^{\circ}$ in. final establece un efecto liberatorio para los sujetos obligados que cumplan con los deberes de comunicación del art. $3^{\circ}$ in. $1^{\circ}$ ya analizados. En este sentido, la información proporcionada por los sujetos obligados de buena fe y en conformidad a la ley, les eximirá de toda responsabilidad legal. Esta norma cristaliza el segundo aspecto del criminal compliance (aspecto procesual represivo) pues establece un especial atractivo para la persona jurídica respectiva de establecer este programa de compliance al interior de la organización. Conjuntamente con ello se cumple además el tercer aspecto del criminal compliance (aspecto económico), excluyendo los daños de reputación derivados de una posible condena penal por concepto de lavado de activos. ${ }^{27}$

Con todo, el legislador ha empleado una estrategia particular para determinar y especificar los deberes de compliance en materia de lavado de activos. Junto a las obligaciones establecidas por la Ley $\mathrm{N}^{\circ} 19.913$, tanto la $\mathrm{UAF}^{28}$ como otros organismos sectoriales entre los cuales se cuenta la Superintendencia de Bancos e Instituciones Financieras (en adelante: "SBIF") ${ }^{29}$ y la Superintendencia de Valores y Seguros (en adelante: "SVS") ${ }^{30}$ han establecido mediante sus circulares y demás resoluciones otros deberes de organización con vistas a la prevención de lavado de activos, que vienen en complementar las normas de la ley en comento.

El más importante de ellos es la forma a través de la cual se cumple con el primer deber de información contemplado en el art. $3^{\circ}$ in. $2^{\circ}$ Ley $\mathrm{N}^{\circ}$ 19.913: el principio "conoce a tus clientes" o "know your customer" (en adelante: "KYC"). Los sujetos obligados deberán tener información suficiente sobre la verdadera identidad del cliente, tanto al momento de iniciar

\footnotetext{
${ }^{27}$ Para las funciones del criminal compliance vid. supra capítulo 1.

${ }^{28}$ Vid. art. $2^{\circ}$ lit. e) y f) Ley $\mathrm{N}^{\circ} 19.913$ y las numerosas circulares dictadas por la UAF en cumplimiento de esta norma, disponibles en www.uaf.cl/legislacion/norm_sector.aspx (último acceso el 15 de agosto de 2017).

${ }^{29}$ Vid. la Recopilación Actualizada de Normas de la SBIF, especialmente en su capítulo 1-14 sobre Prevención del Lavado de Activos y del Financiamiento del Terrorismo, y en su capítulo 1-16, sobre Operaciones con Personas Expuestas Políticamente (PEP).

${ }^{30}$ Vid. especialmente Circular $N^{\circ} 1.809$ del 10 de agosto de 2006 de la SVS, que imparte instrucciones sobre prevención de lavado de activos y de financiamiento del terrorismo, cuya última modificación es la Circular $\mathrm{N}^{\circ} 2.070$ del 19 de abril de 2012 de la SVS que introduce normas acerca de operaciones con PEP.
} 
la relación comercial ${ }^{31}$ con este como durante toda la vigencia de la misma. Esto se traduce en un proceso de aceptación de clientes que incluya recabar sus antecedentes (en caso de personas jurídicas razón social, personas que la integran, domicilio, giro, datos de contacto, etc.) así como establecer un sistema de seguimiento o monitoreo permanente de sus operaciones. $^{32}$

Las circulares establecen además la obligación de establecer una política de selección y capacitación permanente de personal con el objeto de contar con una colaboración efectiva por parte de todos los miembros de la organización en las tareas de prevención de blanqueo. En las circulares de la UAF se establece además el contenido y periodicidad de las capacitaciones. ${ }^{33}$

Estos deberes de organización no son meras recomendaciones sino que normas vinculantes para sus destinatarios, e imponen obligaciones de compliance que en caso de contravención van aparejadas de importantes sanciones pecuniarias. ${ }^{34}$

Han sido así los entes de la administración pública quienes han precisado la forma como debe implementarse el sistema de compliance en materia de lavado de activos, entregando pautas claras a los sujetos obligados sobre cómo deben organizarse internamente para prevenir el aprovechamiento de sus estructuras para la comisión de delitos. La especificación de los deberes de organización contribuye por una parte a la efectividad de la norma, al establecer herramientas concretas y eficaces de control; mientras que aporta por la otra a la seguridad jurídica, al establecer normas claras de organización para sujetos obligados.

\section{La experiencia comparada}

Aparte de nuestro ordenamiento jurídico, los programas de compliance han sido previstos expresamente en los ordenamientos jurídicos de Italia (art. 6 D. Lgs. n. 231/2001), Austria (§ 3 in. $3^{\circ} \mathrm{N}^{\mathrm{o}} 2$ Ley de Responsabilidad de Asociaciones austríaca), Suiza (art. 102 - ex $100^{\text {quater }}$ - Código Penal suizo), España (art. 31 ${ }^{\text {quater }}$ Código Penal español), Reino Unido ( 8 (4) Corporate Manslaughter and Corporate Homicide Act y $\S 7$ UK Bribery Act) y los Estados Unidos de América (\$8C2.5. (f)(1) United States Federal Sentencing Guidelines y Sarbanes Oxley Act), entre otros. ${ }^{35}$

\footnotetext{
${ }^{31}$ Acerca del momento en que deben cumplirse los deberes de KYC por parte de los sujetos obligados vid. TOSO MILOS, Ángela, "La regulación de prevención del lavado de activos relativa al momento en que se debe conocer a los clientes. Reflexiones derivadas de su aplicación por el banco emisor de un crédito documentario", Revista Ius et Praxis, año $22 \mathrm{~N}^{\circ} 2$ (2016), pp. 19-52, pp. 24 y ss.

${ }^{32}$ Este deber está contemplado en numerosas circulares, especialmente en la Circular $\mathrm{N}^{\circ} 49$ de la UAF del 3 de diciembre de 2012, pp. 4 y ss. Cfr. TOSO MILOS, "Blanqueo de capitales", cit. nota n²5, pp. 421 y ss.

${ }^{33}$ Circular $\mathrm{N}^{\circ} 49$ de la UAF del 3 de diciembre de 2012, pp. 8 y ss.

${ }^{34}$ Vid. sistema sancionatorio en los arts. 20 y ss. Ley $\mathrm{N}^{\circ} 19.913$, y en el art. ${ }^{\circ} 19$ de la Ley General de Bancos, D.F.L. $\mathrm{N}^{\circ} 3$ de 1997.

${ }^{35}$ La tematización del criminal compliance en la doctrina comparada ha ido a la par de su expansión legislativa. Véase a título ejemplar las monografías de GÓMEZ-JARA DÍEZ, Carlos, La culpabilidad penal de la empresa, Madrid: Marcial Pons Ediciones Jurídicas y Sociales, 2005, pp. 254 y ss., pp. 270 y ss.; y de NIETO MARTÍN, La Responsabilidad Penal, cit. nota n ${ }^{\circ}$ 3, pp. 215 y ss.; así como los artículos contenidos en KUHLEN, Lothar, MONTIEL, Juan Pablo, ORTÍZ DE URBINA GIMENO, Íñigo (Eds.), Compliance y teoría del Derecho Penal, Madrid: Marcial Pons Ediciones Jurídicas y Sociales, 2013; y en MIR PUIG, Santiago, CORCOY BIDASOLO,
} 
Es interesante revisar la experiencia comparada acerca de la forma como se les dota de contenido a los modelos de compliance. Para ello se analizarán en primer lugar a dos modelos vigentes en los Estados Unidos de América, elección que se basa en la antigua experiencia con que cuenta ese ordenamiento jurídico con sistemas de autorregulación forzada. Posteriormente se analizará un modelo vigente en el Reino Unido, el cual debido a su extenso campo de aplicación tiene directa relevancia para nuestro país. Finalmente se hará una somera exposición del modelo español, recientemente introducido en esa legislación, el cual es especialmente relevante debido a su natural paralelismo con el modelo chileno.

\subsection{Estados Unidos}

La responsabilidad penal de las personas jurídicas tuvo su origen histórico en los Estados Unidos con el caso "New York Central \& Hudson River Railroad Co. v. United States" hace ya más de una centuria. ${ }^{36}$ En este contexto, los sistemas de compliance han alcanzado un alto desarrollo. Normas tanto a nivel federal como local contemplan modelos de compliance como atenuantes de sanciones penales. Ejemplo de ello son la Sarbanes-Oxley-Act 2002 (en adelante: "SOA") ${ }^{37}$ y el capítulo 8 de las Federal Sentencing Guidelines (en adelante: "USFSG”).

A fines de la década de los 90, distintos escándalos empresariales (entre otros los de Enron y Worldcom) ocasionaron nuevos esfuerzos de los poderes públicos para acentuar el régimen de sanciones contra las personas jurídicas. El gobierno del entonces presidente Georg W. Bush reaccionó con la creación de la Corporate Fraud Task Force, mientras que el Congreso de los Estados Unidos por su parte dictó la SOA, la cual establece deberes de vigilancia y sistemas de compliance más estrictos para las corporaciones. ${ }^{38}$

Mediante una regulación altamente detallada, la SOA establece el deber de crear estructuras de compliance para fortalecer la dirección y control empresarial, lo cual debe reflejarse en todas las funciones y niveles de la empresa. La ley le impone normas de comportamiento entre otras a empresas que cotizan en bolsas de valores estadounidenses y a sociedades auditoras externas, con el objeto de evitar acciones fraudulentas y auditorias de estados

\footnotetext{
Mirentxu, GÓMEZ MARTíN, Víctor (dirs.), Responsabilidad de la Empresa y Compliance. Programas de prevención, detección y reacción penal, Madrid: Edisofer S. L., 2014. Véase además en la literatura germana a ENGELHART, Marc, Sanktionierung von Unternehmen und Compliance: Eine rechtsvergleichende Analyse des Straf- und Ordnungswidrigkeitenrechts in Deutschland und den USA, $2^{a}$ edición, Berlin: Duncker \& Humblot, 2012, pp. 285 y ss., pp. 496 y ss. pp. 590 y ss., pp. 711 y ss.; HAUSCHKA, Christoph (ed.), Corporate Compliance. Handbuch der Haftungsvermeidung im Unternehmen, $2^{a}$ edicion, München: C.H. Beck, 2010; y ROTSCH, Thomas (ed.), Criminal Compliance: Handbuch, Baden-Baden: Nomos, 2015.

36212 U.S. 481, 29 S. Ct. 304, 53 L. Ed. 613 (1909). Resumen en ORTIZ DE URBINA GIMENO, Íñigo, "Responsabilidad penal de las personas jurídicas: The American Way", en: MIR PUIG, Santiago, CORCOY BIDASOLO, Mirentxu, GÓMEZ MARTÍN, Víctor (dirs.), Responsabilidad de la Empresa y Compliance. Programas de prevención, detección y reacción penal, Madrid: Edisofer S. L., 2014, pp. 35-88, pp. 41 y ss.

${ }^{37}$ Pub.L. 107-204, 116 Stat. 745.

${ }^{38}$ Un análisis histórico en NANDA, Ved, "Corporate Criminal Liability in the United States: Is a New Approach Warranted?”, en: PIETH, Mark; IVORY, Radha, Corporate Criminal Liability. Emergence, Convergence and Risk, Heidelberg: Springer, 2011, pp. 63-89, pp. 64 y ss.
} 
Polit. crim. Vol. 13, № 25 (Julio 2018) Art. 6, pp. 208-232.

[http://www.politicacriminal.cl/Vol_13/n_25/Vol13N25A6.pdf]

financieros incorrectas. La efectividad del sistema de controles debe acreditarse mediante una documentación comprehensiva. ${ }^{39}$

El campo de aplicación de la SOA abarca a todas las empresas cotizadas en bolsas de valores de los Estados Unidos, es decir, todas aquellas cuyos títulos sean transados en la "New York Stock Exchange" (NYSE), "National Association of Securities Dealers Automated Quotation" (NASDAQ) y "American Stock Exchange" (AMEX) o sean ofrecidos en forma pública en los Estados Unidos. También se incluyen aquellas empresas sometidas a la supervigilancia de la "Securities and Exchange Commission" (en adelante: "SEC"). En este esquema, el domicilio de la empresa es en principio irrelevante, pues también sociedades chilenas pueden resultar afectadas, en caso de que ella o su sociedad matriz se encuentren bajo supervisión de la SEC.

Por otra parte, las USFSG son un conjunto de normas dictadas por la United States Sentencing Commission que tienen por objeto uniformar a nivel federal los criterios de determinación de las penas y medidas de seguridad. ${ }^{40} \mathrm{El}$ capítulo 8 establece normas para la determinación de las penas y medidas de seguridad aplicables a organizaciones, las cuales pueden consistir en la reparación del daño causado por la conducta criminal ("remedying harm from criminal conduct”, §8B USFSG), la multa penal ("fines", §8C USFSG) y la condena condicional (“organizational probation", §8D USFSG).

La implementación de un programa efectivo de compliance y de ética está prevista como una importante atenuante en $\S 8 \mathrm{C} 2.5$. (f)(1) USFSG, pudiendo ocasionar una reducción de hasta un $60 \%$ de la multa base aplicable al delito. Para ello debe cumplir con los requisitos mínimos establecidos en $\S 8$ B2.1. USFSG. En ese sentido, debe ejercer una debida diligencia en la prevención y detección de conductas criminales a través de las siguientes medidas: (1) estableciendo estándares y procedimientos para prevenir y detectar conducta criminal; (2) involucrando a los directivos, personal de alto nivel y especialistas en el diseño, implementación y supervisión del programa; (3) ejerciendo una política de selección de personal adecuada a través de herramientas de due dilligence; (4) comunicando periódicamente y de una forma práctica los estándares y procedimientos a las personas involucradas mediante capacitaciones y difusión ad-hoc; (5) monitoreando el cumplimiento del programa, evaluando periódicamente su efectividad y estableciendo un sistema de denuncias para los empleados y agentes de la organización que garantice su anonimato; (6) creando incentivos y medidas disciplinarias para asegurar su cumplimiento; y (7) tomar

\footnotetext{
${ }^{39}$ Un resumen de los preceptos más importantes de la ley en comento en STRAUCH, Mark, "Der SarbanesOxley Act und die Entwicklungen im US-Aufsichtsrecht", Neue Zeitschrift für Gesellschaftsrecht, fascículo $\mathrm{n}^{\circ} 20$ (2003), pp. 952-956, pp. 952 y ss.

${ }^{40}$ En virtud del Capítulo 18, §3553 del Código de los Estados Unidos en su versión del año 2000, las USFSG tenían fuerza vinculante para los jueces federales de los Estados Unidos en la condena tanto de personas naturales como de personas jurídicas. Sin embargo, la Corte Suprema de los Estados Unidos, en su sentencia United States v. Booker (543 U.S. 220, 245 (2005)), decidió que la obligatoriedad de su aplicación era inconstitucional por vulneración de la Sexta Enmienda, la cual consagra el derecho a un juicio previo frente a un jurado. Ver además Apprendi v. New Jersey, 530 U.S. 466 (2000) y Blakely v. Washington, 542 U.S. 296 (2004). Vid. JOHNSON, Timothy, "Sentencing Organizations after Booker", The Yale Law Journal, T. 116, No 3 (2006), pp. 632-666, p. 636.
} 


\section{BEDECARRATZ, Francisco. "La indeterminación del criminal compliance} y el principio de legalidad".

medidas tras la detección de conductas criminales. ${ }^{41}$ Cabe destacar que algunos de estos criterios son asimilables a los seis principios que informan los "procedimientos adecuados" establecidos en la sección 7 UKBA. ${ }^{42}$

Existen sin embargo dos causales que excluyen la reducción de la pena de los programas de compliance y ética. La organización debe en primer lugar detectar el hecho punible y además auto-denunciarse frente a las autoridades gubernamentales competentes. En caso de que la corporación haya demorado injustificadamente la auto-denuncia ("unreasonably delayed reporting”), no se aplicará la rebaja (§8C2.5. (f)(2) USFSG). Lo mismo ocurre en caso de que un directivo, personal de alto nivel de la organización o especialista en el diseño e implementación del programa ha participado en el delito, lo ha tolerado tácitamente o era conscientemente ignorante de su comisión (\$8C2.5. (f)(3) USFSG).

\subsection{Reino Unido: La Corporate Bribery Act}

La "Bribery Act 2010" (en adelante: “UKBA") fue aprobada el 8 de abril de 2010, entrando en vigor en el Reino Unido el $1^{\circ}$ de julio de $2011 .{ }^{43}$ Esta ley ha endurecido considerablemente las sanciones aplicables a empresas por delitos vinculados a la corrupción.

La UKBA describe en sus $\S \S 1^{\circ}$ a $8^{\circ}$ cuatro contravenciones: el cohecho activo y pasivo, el cohecho de funcionarios públicos extranjeros y la omisión de impedir un cohecho al interior de la organización comercial, cuando este se haya efectuado en su propio beneficio. Como penas se prevén en su $§ 11$ multas penales, cuya cuantía no está limitada por la ley. Su análisis resulta especialmente importante por el sustancial efecto probatorio para las organizaciones que tienen los programas de compliance. ${ }^{44}$

Según el $\$ 7$ UKBA, una organización comercial relevante ("relevant comercial organisation") es culpable de no impedir cohecho, en caso de que una persona asociada a la misma soborne a otra con la intención de obtener o retener un negocio o una ventaja en la conducción de negocios para la organización. En este caso, para la organización operará no una presunción de inocencia sino que de culpabilidad, pues la organización responderá por el sólo hecho de haberse cometido un cohecho activo (simple o a funcionario extranjero) por

\footnotetext{
${ }^{41}$ Cfr. enumeración en GÓMEZ-JARA DÍEZ, La culpabilidad, cit. nota $\mathrm{n}^{\circ}$ 35, p. 257; ARTAZA VARELA, "Sistemas de prevención", cit. nota $\mathrm{n}^{\circ} 11$, pp. 559 y ss. Los criterios específicos son analizados por ENGELHART, Sanktionierung von Unternehmen, cit. nota ${ }^{\circ} 35$, pp. 163 y ss.; ARTAZA VARELA, Osvaldo, La Empresa como Sujeto de Imputación de Responsabilidad Penal. Fundamentos y límites, Madrid: Marcial Pons, 2013, pp. 117 y ss.

${ }^{42}$ Guía del Ministerio de Justicia Británico sobre la UKBA: Bribery Act 2010 Guidance, disponible en www.justice.gov.uk/downloads/legislation/bribery-act-2010-guidance.pdf (último acceso el 15 de agosto de 2017).

${ }^{43}$ La UKBA es aplicable en Inglaterra, Gales, Escocia e Irlanda del Norte. $§ 19$ UKBA.

${ }^{44}$ Cabe destacar que un motivo más para el análisis de la norma es su aplicabilidad al interior de nuestro país. La sección 7 (5) UKBA incluye dentro de las organizaciones comerciales relevantes ("relevant comercial organisation") no solo a empresas y asociaciones británicas, sino que a empresas y asociaciones extranjeras que ejerzan en todo o parte un negocio en el Reino Unido ("carries on a business or part of a business"). Por su parte, la sección 12 № 5 UKBA establece que para la aplicabilidad de la sección 7 (no impedir un soborno) es indiferente que los actos descritos hayan tenido lugar en el Reino Unido o fuera del mismo.
} 
parte de una persona ligada a ella. Esto constituye en toda regla un caso de responsabilidad penal objetiva de la organización.

Sin embargo, la sección 7 (2) UKBA consagra una excepción perentoria ("defence") en favor de la organización. Establece la posibilidad de que esta se exima de responsabilidad, si prueba que ha implementado procedimientos adecuados ("adequate procedures") para prevenir que personas asociadas a ella ejecuten las conductas penadas por la sección 7 UKBA. ${ }^{45}$

La UKBA no define lo que debe entenderse bajo el concepto de "procedimientos adecuados", razón por la cual el Reino Unido publicó en marzo del año 2011 una Guía confeccionada por el Ministerio de Justicia del Reino Unido, explicando el sentido y alcance de ciertas disposiciones, todo ello en conformidad con la sección 9 UKBA. ${ }^{46}$ En este documento se establece que los "procedimientos adecuados" a implementar por parte de la organización deben reflejar seis principios: los procedimientos deben ser proporcionales al riesgo de cohecho que enfrenta la organización y a la naturaleza, escala y complejidad de sus actividades (proporcionate procedures); los directivos principales deben comprometerse con las tareas de prevención de cohecho de las personas asociadas a la organización (top-level commitment); un análisis del riesgo de cohecho al que se está expuesto que sea periódico, informado y documentado (risk assessment); una selección y examen proporcionado y basado en el riesgo de las relaciones comerciales (due diligence); el aseguramiento de que las políticas y procedimientos de prevención del delito de cohecho han sido difundidos y comprendidos al interior de la organización (communication - including training); y un constante monitoreo, evaluación y revisión de los procedimientos de prevención de cohecho (monitoring and review). ${ }^{47}$

La guía establece así una serie de definiciones, principios y procedimientos concretos a implementar por las organizaciones comerciales relevantes, que ayudan en la efectividad de las medidas preventivas del delito de cohecho y proporcionan seguridad jurídica a los gobernados.

\subsection{España}

La responsabilidad penal de las personas jurídicas fue introducida en el Código Penal español (en adelante: “CPE”) en virtud de la Ley Orgánica (en adelante: “L.O.”) 5/2010 del 22 de junio de 2010. ${ }^{48}$ Piedra angular del modelo de atribución lo constituye el art. 31 bis CPE, el cual, similar a lo establecido en la Ley № 20.393, prevé dos modalidades de comisión: la primera de ellas es la comisión por representantes legales, personas investidas de capacidad de decisión o con facultades de decisión, organización o control al interior de la persona

\footnotetext{
${ }^{45}$ WITTIG, Petra, Wirtschaftsstrafrecht, $3^{a}$ edición, München: C.H. Beck, 2014, § 8, $\mathrm{N}^{\circ} 12$.

${ }^{46}$ Bribery Act 2010 Guidance, cit. nota $\mathrm{n}^{\circ} 42$.

${ }^{47}$ Bribery Act 2010 Guidance, cit. nota ${ }^{\circ}$ 42, p. 20 y ss. Cfr. además a KAPPEL, Jan; LAGODNY, Otto, "Der UK Bribery Act - Ein Strafgesetz erobert die Welt? -Ein kritischer Diskussionsanstoß-”, Strafverteidiger, T. 32, fascículo n 11 (2012), pp. 695-701, p. 697. Cfr. HUGGER, Heiner; RÖHRICH, Raimund, "Der neue UK Bribery Act und seine Geltung für deutsche Unternehmen”, Betriebs-Berater, año 2010, pp. 2643-2647, pp. 2645 y s.; y además a DEISTER, Jochen; GEIER, Anton, "Der UK Bribery Act 2010 und seine Auswirkungen auf deutsche Unternehmen”, Corporate Compliance Zeitschrift, fascículo N 1 (2011), pp. 12-18, pp. 15 y ss.

${ }^{48}$ En vigor desde el 23 de diciembre de 2010.
} 


\section{BEDECARRATZ, Francisco. "La indeterminación del criminal compliance y el principio de legalidad".}

jurídica (sujetos en posición apical). La segunda modalidad prevé la comisión por sujetos sometidos a la autoridad de las personas mencionadas en la modalidad anterior (sujetos subalternos). En este último caso se requiere además que el hecho punible haya podido ser cometido a causa del incumplimiento grave de los deberes de supervisión, vigilancia y control por los sujetos en posición apical. ${ }^{49}$

La norma central de atribución del art. 31 bis se encuentra complementada por los arts. 31 ter, 31 quater y 31 quinquies, todos ellos del $\mathrm{CPE}$, que regulan otros requisitos para la aplicabilidad de una sanción penal a la persona jurídica.

Cabe desde ya advertir una diferencia entre el modelo de imputación español y el chileno. En el español, el incumplimiento de los deberes de supervisión, vigilancia y control se exige como requisito sólo en la comisión por un sujeto subalterno y no en la comisión por parte de un representante legal o de personas con facultades decisorias, de organización o de control. En cambio, en el modelo chileno, el art. $3^{\circ}$ in. $1^{\circ}$ Ley $\mathrm{N}^{\circ} 20.393$ exige el incumplimiento de los deberes de dirección y supervisión en ambas variantes de comisión. ${ }^{50}$

El art. 31 bis CPE establece la posibilidad de que la persona jurídica se exima de responsabilidad penal cuando haya adoptado y ejecutado eficazmente, previo a la comisión del delito, de un modelo de organización y gestión idóneo o adecuado para prevenir delitos de la misma naturaleza del que fue cometido o para reducir de forma significativa el riesgo de comisión. En caso de que el delito haya sido perpetrado por individuos sometidos a supervisión, vigilancia o control, la adopción y ejecución efectiva del modelo es por si sola capaz de producir la exención de la persona jurídica; por el contrario, en caso de comisión por un representante legal o por personas naturales con facultades decisorias, de organización o control al interior de la organización, resulta además necesario que se cumplan las demás condiciones enumeradas en el art. 31 bis, apartado 2, CPE. Ello, pues la comisión de un delito por parte de los líderes de la persona jurídica se identifica con la comisión de un delito por parte de la persona jurídica misma, al erigirse estas personas como su órgano decisorio. ${ }^{51}$ Por lo tanto, la organización debe realizar una mayor actividad probatoria para eximirse de responsabilidad, demostrando que los controles internos han sido ejecutados correctamente

\footnotetext{
49 Cfr. SILVA SÁNCHEZ, Jesús-María, "Die strafrechtliche Haftung von juristischen Personen nach spanischem Strafrecht", en: KEMPF, Eberhard; LÜDERSSEN, Klaus; VOLK, Klaus (Eds.), Unternehmensstrafrecht, Berlin: Walter de Gruyter, 2012, pp. 59-70, p. 63.

${ }^{50}$ NEIRA PENA, "La efectividad de los criminal compliance programs", cit. $\mathrm{n}^{\circ}$ 1, p. 482. Sobre el problema de indeterminación de los deberes de dirección, supervisión y control en el modelo español (art. 31 bis apartado 1 lit. b) CPE), vid. BEDECARRATZ SCHOLZ, Rechtsvergleichende Studien, cit. nota n 22, pp. 280 y s.; DEL ROSAL BLASCO, Bernardo, "La delimitación típica de los llamados hechos de conexión en el nuevo artículo 31 bis, no 1, del Código Penal”, Cuadernos de Política Criminal, N 103 (2011), pp. 41-94, pp. 90 y s.; y ROBLES PLANAS, Ricardo, "Strafe und juristische Person. Eine Kritik des Art. 31bis des spanischen Strafgesetzbuches”, ZIS, N 7 (2012), pp. 347-360, p. 356 (ver nota 58 del artículo). Vid. supra capítulo 2.1.

${ }^{51}$ Esta es la idea base de la identification doctrine, la cual ha constituido el fundamento histórico para la sanción penal de las empresas en Inglaterra. Según esta teoría, la empresa se materializa a través de aquellos empleados que actúan como sus cabezas pensantes (controlling mind). Luego, se le imputa a la empresa el elemento material (actus reus) y el elemento subjetivo (mens rea) perteneciente sólo a aquellas personas situadas en los estamentos más altos de la empresa. Vid. BLOY, Duncan; PARRY, Philip et. al. (eds.), Bloy and Parry's Principles of Criminal Law, $4^{a}$ edición, Londres: Routledge Cavendish, 2000, p. 139. Cfr. Law Commission, Report on Involuntary Manslaughter, $\mathrm{N}^{\circ} 237,1996, \S 6.27$.
} 
Polit. crim. Vol. 13, № 25 (Julio 2018) Art. 6, pp. 208-232.

[http://www.politicacriminal.cl/Vol_13/n_25/Vol13N25A6.pdf]

y que, en consecuencia, no hay un fracaso organizacional de la persona jurídica. Aún más importante es el requisito de que el modelo de prevención haya sido eludido fraudulentamente por los autores (art. 31 bis, apartado 2, condición 3. ${ }^{\mathrm{a}} \mathrm{CPE}$ ).

La norma exige una adopción e implementación eficaz de los modelos, lo cual constituye un punto esencial para determinar si generarán una exención de responsabilidad para la persona jurídica o no. Con todo, un problema que ha suscitado la discusión de la doctrina española es precisar lo que se entiende por un modelo de prevención de delitos eficaz. ${ }^{52}$ A falta de una definición o de reglas establecidas al efecto por el legislador, la Fiscalía General del Estado español (en adelante: "FGE") ha identificado una serie de criterios para evaluar esta eficacia en su Circular 1/2016 del 22 de enero de 2016, sobre la Responsabilidad Penal de las Personas Jurídicas conforme a la Reforma del Código Penal efectuada por Ley Orgánica 1/2015 (en adelante: "Circular 1/2016"). ${ }^{53}$

El contenido del modelo de organización y gestión está especificado en el art. 31 bis apartado 5 CPE, el cual fue introducido a través de la L.O. 1/2015 y no era parte del contenido original de precepto. ${ }^{54} \mathrm{Al}$ igual que en el ejemplo chileno, el art. 31 bis apartado $5 \mathrm{CPE}$ enuncia el contenido de los programas de compliance que deben implementar las personas jurídicas. La norma española enumera genéricamente los requisitos mínimos de los modelos de organización y gestión, sin establecer una regulación detallada sobre el contenido específico o su forma de adopción e implementación. Así, la norma se asemeja al art. 4 Ley $\mathrm{N}^{\circ} 20.393$ desde una doble perspectiva: en cuanto a los elementos enunciados y al insuficiente detalle de los mismos. ${ }^{55}$

Para hacer frente a esta indeterminación, la FGE ha identificado como criterio interpretativo la normativa sectorial que establece obligaciones específicas de organización y gestión de riesgo. Ejemplo de dicha normativa es el Real Decreto 304/2014, de 5 de mayo, por el que se aprueba el Reglamento de la Ley 10/2010, de 28 de abril, de prevención del blanqueo de

\footnotetext{
52 Vid. criterios enumerados en NEIRA PENA, "La efectividad de los criminal compliance programs", cit. nota $\mathrm{n}^{\circ} 1$, pp. 477 y ss. Cfr. GUTIÉRREZ PÉREZ, Elena, "Los compliance programs como eximente o atenuante de la responsabilidad penal de las personas jurídicas. La 'eficacia e idoneidad' como principios rectores tras la reforma de 2015", Revista General de Derecho Penal, no24 (2015), pp. 1-24, pp. 12 y ss.

${ }^{53}$ Circular 1/2016, p. 51 y ss.

${ }^{54}$ Art. 31 bis apartado 5 CPE "Los modelos de organización y gestión a que se refieren la condición 1.a del apartado 2 y el apartado anterior deberán cumplir los siguientes requisitos:

$1 .^{\circ}$ Identificarán las actividades en cuyo ámbito puedan ser cometidos los delitos que deben ser prevenidos.

2. ${ }^{\circ}$ Establecerán los protocolos o procedimientos que concreten el proceso de formación de la voluntad de la persona jurídica, de adopción de decisiones y de ejecución de las mismas con relación a aquéllos.

3. ${ }^{\circ}$ Dispondrán de modelos de gestión de los recursos financieros adecuados para impedir la comisión de los delitos que deben ser prevenidos.

4..$^{\circ}$ Impondrán la obligación de informar de posibles riesgos e incumplimientos al organismo encargado de vigilar el funcionamiento y observancia del modelo de prevención.

5. ${ }^{\circ}$ Establecerán un sistema disciplinario que sancione adecuadamente el incumplimiento de las medidas que establezca el modelo.

6. ${ }^{\circ}$ Realizarán una verificación periódica del modelo y de su eventual modificación cuando se pongan de manifiesto infracciones relevantes de sus disposiciones, o cuando se produzcan cambios en la organización, en la estructura de control o en la actividad desarrollada que los hagan necesarios."

${ }^{55}$ Vid. supra pp. 5 y ss.
} 


\section{BEDECARRATZ, Francisco. "La indeterminación del criminal compliance} y el principio de legalidad".

capitales y de la financiación del terrorismo. ${ }^{56}$ Se ha buscado así dotar de mayor contenido a los programas a través de normativa de naturaleza infra-legal, pero ello es posible sólo respecto de ciertos riesgos delictivos y tipos de personas jurídicas, existiendo importantes vacíos respecto de materias sobre las cuales no se ha dictado una regulación similar. Con todo, se echa de menos una referencia legal expresa que proporcione seguridad jurídica, en relación con la forma con que deben cumplirse las obligaciones establecidas en el art. 31 bis apartado $5 \mathrm{CPE}$.

\section{Propuestas de solución}

Los modelos expuestos ofrecen dos alternativas para solucionar el problema de indeterminación de los modelos de criminal compliance. Estos son el sistema de certificaciones y la concretización a través de normativa infra-legal. De un análisis de esta dicotomía pueden extractarse mecanismos de solución a la problemática de indeterminación legal en nuestro ordenamiento jurídico.

\subsection{Los sistemas de certificaciones}

Organismos independientes pueden analizar la implementación de los requisitos legales y evaluar el apego a la norma en el caso concreto. Tal es el mecanismo seguido por el art. $4^{\circ}$ $\mathrm{N}^{\circ} 4$ ) lit. b) Ley $\mathrm{N}^{\circ}$ 20.393, que establece la posibilidad de que la adopción e implementación del modelo sea certificado mediante empresas externas de auditoría $\mathrm{u}$ otros organismos similares registrados al efecto por la Superintendencia de Valores y Seguros. ${ }^{57} \mathrm{La}$ certificación tendrá por objeto el cumplimiento de los numerales 1), 2) y 3) del art. $4^{\circ}$, lo cual tendrá directa relación con las características individuales de la persona jurídica. El certificado podrá ser presentado por la persona jurídica en el marco de un proceso penal, como medio de prueba para acreditar el cumplimiento de los deberes de dirección y supervisión. En caso de no existir el certificado, la persona jurídica deberá acreditar el cumplimiento de sus deberes de acuerdo con las reglas generales. ${ }^{58}$

De esta forma, la norma penal es especificada a través de la práctica auditora, la cual contribuye a que los sujetos pasivos conozcan con mayor precisión y aplicado a su caso concreto el estándar de autorregulación exigido por la ley.

Sin embargo, el mercado no necesariamente ofrecerá los incentivos adecuados para que las empresas realicen un control estricto. Ciertas sociedades auditoras o certificadoras pueden ofrecer certificados de compliance, sin realizar procesos de certificación serios que comprendan controles de diseño o de efectividad del programa, ofreciendo así verdaderos seguros en contra de la persecución penal estatal. Las certificaciones podrían producir el

\footnotetext{
${ }^{56}$ Circular 1/2016, pp. 42 y s.

${ }^{57}$ NIETO MARTÍN, Adán, "Cosmetic Use and Lack of Precision in Compliance Programs: Any Solution?", Eucrim, $\mathrm{n}^{\circ} 3$ (2012), pp. 124-127, pp. 124 y s.; características específicas del sistema de certificaciones chileno en PIÑA ROCHEFORT, Modelos de prevención, cit. nota n ${ }^{\circ}$ 6, p. 89 y ss.

${ }^{58}$ Vid. HERNÁNDEZ BASUALTO, "La introducción de la responsabilidad penal", cit. nota n ${ }^{\circ} 14$, pp. 226 y s. Cfr. MATUS ACUÑA, Jean Pierre, "Sobre el valor de las certificaciones de adopción e implementación de modelos de prevención de delitos frente a la responsabilidad penal de las personas jurídicas", Revista Chilena de Derecho y Ciencias Penales, Vol. II, N 2 (2013), pp. 11-22, pp. 20 y ss.
} 
efecto de patentes de corso ${ }^{59}$ para empresas criminógenas y elevar aún más el riesgo de comisión de delitos. Así concebido el sistema, es poco en lo que contribuye a determinar el mandato legal y puede incluso causar el surgimiento de un sistema de certificaciones fraudulento.

Para solucionar esta dificultad, se impone la necesidad de estandarización de la función certificadora en base a normas objetivas. Por ejemplo, el Instituto de Auditores en Alemania (Institut der Wirtschaftsprüfer in Deutschland e.V.) publicó en abril de 2011 los estándares de auditoría IDW PS 980, estableciendo normas claras para la auditoría de sistemas de gestión de compliance en ese país. A nivel internacional se ha dictado la norma ISO 19600: 2015 "Sistemas de gestión de compliance. Directrices", que orientan sobre la implementación, evaluación, mantenimiento y mejoramiento de sistemas de compliance y que ha sido incorporado por algunos países en reemplazo de estándares locales. Los certificados otorgados pueden ser esgrimidos como un medio de prueba acerca del cumplimiento de la obligación de compliance, lo cual puede a su vez contribuir para acreditar una atenuante o eximente de responsabilidad penal. ${ }^{60}$

Cabe aclarar que, si bien es cierto que los sistemas de certificaciones pueden servir como paliativos al problema de indeterminación, no es menos cierto que los estándares que pueden establecer los organismos certificadores no necesariamente tendrán rango normativo. Debido a ello, los entes persecutores penales pueden desestimar las certificaciones e igualmente enjuiciar y obtener una condena de la organización.

Una variante exhibe el art. 6 apartado 3 D. Lgs. n. 231/2001 de Italia, el cual establece la estandarización de los programas de compliance mediante la intervención de la administración pública: "Los modelos de organización y gestión podrán ser adoptados, garantizando las exigencias del apartado 2, a partir de los códigos de conducta redactados por las asociaciones representantes del ente, presentándolos ante el Ministerio de Justicia, el cual en concierto con el ministerio del ramo correspondiente, podrá formular, dentro de los siguientes 30 días, observaciones sobre la idoneidad del modelo de prevención de delitos."61 En ese sentido, la administración pública puede estandarizar la concretización de los preceptos legales sobre compliance mediante decisiones específicas, lo cual también puede contribuir a tutelar el principio penal de lex certa. ${ }^{62}$

\subsection{El complemento a través de normativa infra-legal}

Un paliativo a mi juicio más efectivo lo constituye el establecimiento de estándares de cumplimiento mediante normativa de categoría infra-legal, en la cual se establezca el contenido específico de los modelos de prevención de delitos. De esta forma se asegura la instauración de estándares técnicamente adecuados según la actividad que realiza y el riesgo

\footnotetext{
59 También calificadas como "una suerte de Bula papal". MATUS ACUÑA, "Sobre el valor de las certificaciones", cit. nota $n^{\circ}$ 58, p. 20; NIETO MARTÍN, "Cosmetic use”, cit. nota n 57, p. 124.

${ }^{60}$ Ya ha sido advertido que las certificaciones deben constituir sólo un medio de prueba y no eximentes de responsabilidad penal, debido a razones procesuales y de efectividad del Derecho Penal. MATUS ACUÑA, "Sobre el valor de las certificaciones", cit. nota $n^{\circ} 58$, pp. 18 y ss.

${ }^{61}$ Traducción del autor.

${ }^{62}$ Cfr. NIETO MARTÍN, "Cosmetic Use”, cit. nota n 57, p. 125.
} 
BEDECARRATZ, Francisco. "La indeterminación del criminal compliance y el principio de legalidad".

al cual está afecta la persona jurídica. Esta es la solución seguida por la Ley $\mathrm{N}^{\circ} 19.913$, la cual establece expresamente en su art. $2^{\circ}$ lit. e) y f) que organismos sectoriales complementarán y dotarán de contenido a las normas de prevención de lavado de activos, lo cual es cumplido por la SBIF y la SVS.

Lo anterior encuentra un símil en Alemania, donde la Ley General de Bancos (Kreditwesengesetz, KWG) junto con la Ley de Lavado de Activos (Geldwäschegesetz, GwG) disponen las normas generales sobre prevención de lavado de activos. Paralelo a ello, la Autoridad Federal de Supervisión Financiera (Bundesanstalt für Finanzdienstleistungsaufsicht, BaFin), ente regulador financiero dependiente del Ministerio de Finanzas alemán, es la encargada de precisar la forma como se cumplen estos deberes al interior de los bancos e instituciones financieras mediante circulares e instructivos, por ejemplo, precisando los elementos mínimos de un análisis de riesgo para la prevención de lavado de activos. ${ }^{63}$

Ésta técnica no sólo es utilizada en Alemania en materia de lavado de activos. A mayor abundamiento, los requisitos mínimos del manejo del riesgo en institutos de crédito en ese país se regulan a través de la Mindestanforderungen an das Risikomanagement (MaRisk), mientras los requisitos mínimos de la función de compliance en las instituciones del mercado de valores se regula a través de la Mindestanforderungen an die Compliance-Funktion (MaComp). Ambos son cuerpos regulatorios dictados por la BaFin.

Cabe destacar que, en sus versiones iniciales, la Ley $\mathrm{N}^{\circ} 20.393$ que introdujo la responsabilidad penal de las personas jurídicas seguía esta alternativa. En el proyecto inicial del ejecutivo (Boletín $\mathrm{N}^{\circ}$ 6423-07) no se definían los requisitos mínimos de los modelos de prevención, a diferencia del actual art. $4^{\circ}$ de la Ley $N^{\circ} 20.393$. El texto original del art. $4^{\circ}$ entregaba la precisión del contenido a un reglamento dictado por Decreto Supremo expedido por el Ministerio de Hacienda. ${ }^{64}$ Una norma así habría sido preferible a la actual, pues habría otorgado mayor flexibilidad y adaptabilidad para la precisión de los deberes de compliance, permitiendo al mismo tiempo especificar al máximo los deberes de autorregulación.

En caso de establecerse que normativa de categoría infra-legal tenga la función de precisar los modelos de criminal compliance establecidos por la ley, resulta necesario por cierto cumplir con los requisitos establecidos al efecto en el ordenamiento jurídico respectivo. En nuestro país, es el Tribunal Constitucional el órgano ha precisado, a través de su jurisprudencia, las características con que deben contar las leyes penales en blanco para cumplir con las exigencias materiales del principio de legalidad penal, consagrado en el art. $19 \mathrm{~N}^{\circ} 3$ in. final de la Carta Fundamental. ${ }^{65} \mathrm{~A}$ mayor abundamiento, esta alta magistratura ha establecido los siguientes requisitos:

\footnotetext{
${ }^{63}$ Ello se realiza a través de la Circular (Rundschreiben) N 8/2005 (GW), del 23 de marzo de 2005.

${ }^{64}$ Vid. BOFILL GENZSCH, Jorge, "Estructuras de imputación y prevención de delitos al interior de la persona jurídica”, en: WILENMANN VON BERNATH, Javier (coord.), Gobiernos corporativos. Aspectos esenciales de las reformas a su regulación, Santiago: Legal Publishing Chile, 2011, pp. 175-195, pp. 192 y s.

${ }^{65}$ Vid. por todos CURY URZÚA, Enrique, La ley penal en blanco, Bogotá: Editorial Temis, 1988, pp. 57 y ss.
} 
Polit. crim. Vol. 13, № 25 (Julio 2018) Art. 6, pp. 208-232.

[http://www.politicacriminal.cl/Vol_13/n_25/Vol13N25A6.pdf]

- Que la norma legal cuente con el núcleo central de la conducta punible, debiendo describir inmediatamente la acción u omisión que puede ser sancionada con una pena, dejando a la disposición complementaria sólo las condiciones en que eso se hará; ${ }^{66}$

- Que en el mismo texto legal efectúe una remisión expresa a la norma de destino; ${ }^{67}$ y

- $\quad$ Que el precepto infra-legal complementario tenga cierta calidad que satisfaga las exigencias de constitucionalidad, lo cual se traduce por ejemplo en recibir una publicidad semejante a la de la ley formal, aun cuando el precepto infra-legal como tal no lo requiera. ${ }^{68}$

Al momento de dictar normativa complementaria que precise el contenido y forma de cumplimiento de las obligaciones de compliance establecidas en la ley, la administración deberá cumplir con los requisitos constitucionales establecidos para las leyes penales en blanco, con el objeto de garantizar la aplicabilidad y legitimidad de la normativa reglamentaria. ${ }^{69}$

En materia de responsabilidad penal de las personas jurídicas en concreto, cabe destacar que el art. $4^{\circ}$ Ley $\mathrm{N}^{\circ} 20.393$ ya establece el núcleo central del programa de compliance, al establecer sus requisitos mínimos ("[...] deberá contemplar a lo menos lo siguiente: [...]”). Ello debe ser complementado a través de disposiciones reglamentarias, circulares o instructivos emanados de organismos sectoriales, que doten de contenido a las medidas de prevención, detección y comunicación y aseguren un efectivo cumplimiento del espíritu de la ley. ${ }^{70}$ En conformidad con las exigencias establecidas por el Tribunal Constitucional, esta normativa debe contar con una vigencia y publicidad similar a la de la ley formal, incorporándose por último en el art. $4^{\circ}$ una referencia expresa a esta normativa.

\section{Conclusiones}

El criminal compliance se ha transformado en un concepto omnipresente en la literatura sobre la criminalidad empresarial. La presencia de programas de compliance en numerosos sistemas sobre responsabilidad penal de las personas jurídicas no ha hecho sino crecer, como lo demuestra la Ley $\mathrm{N}^{\circ} 20.393$ y más recientemente la reforma al art. 31bis del CPE mediante la L.O. 1/2015 del 30 de marzo de 2015. Esta franca expansión hace especialmente relevante cortar de raíz los problemas de indeterminación de que adolece la técnica legislativa empleada en la consagración de los programas. En nuestro país, este problema se traduce en que no existe mayor precisión sobre la forma como debe implementarse el modelo establecido en el art. $4^{\circ}$ Ley $\mathrm{N}^{\circ} 20.393$, dejando serias lagunas en cuanto al contenido del sistema de prevención de delitos que deberán ser interpretadas por la judicatura. Más aún, dado que el modelo del art. $4^{\circ}$ es meramente facultativo, existe una incertidumbre aún mayor

\footnotetext{
66 Sentencia del Tribunal Constitucional, rol No 24, considerando No 4 (en adelante: "STC 24/4"); STC 1432/30; STC 1443/27.

67 STC 1011/4.

${ }^{68}$ STC 468/8.

${ }^{69}$ CURY URZÚA, Derecho Penal, cit. nota ${ }^{\circ} 12$, pp. 179 y ss.

${ }^{70}$ La precisión de cómo debe estructurarse estas medidas escapa al objeto de estas líneas. Véase al efecto a PIÑA ROCHEFORT, Modelos de prevención, cit. nota $\mathrm{n}^{\circ}$ 6, pp. 1 y ss. y a GARCÍA CAVERO, Percy, Criminal Compliance, Lima: Palestra Editores S.A.C., 2014, pp. 27 y ss.
} 
BEDECARRATZ, Francisco. "La indeterminación del criminal compliance y el principio de legalidad".

en relación con el contenido de programas de criminal compliance que no sigan el modelo propuesto por la ley.

Existen mecanismos a través de los cuales puede subsanarse esta falencia. En el contexto de la UKBA, la guía elaborada por el Ministerio de Justicia británico sobre los "procedimientos adecuados" constituye una herramienta de precisión que está ausente en nuestro ordenamiento jurídico. La labor de la BaFin en Alemania de concretizar a través de su normativa los deberes de los sujetos obligados en materia de prevención de lavado de activos, es también valiosa para dar forma al contenido de los deberes de organización al interior de las instituciones financieras. Y sin ir más lejos, los deberes de criminal compliance impuestos a través de las circulares de la UAF, SBIF y SVS en relación con la prevención del lavado de activos en nuestro país, constituyen también una útil herramienta para determinar si los sujetos obligados cumplen con sus deberes de organización internos y, por lo tanto, si son liberados o no de responsabilidad, en caso de que se cometa un delito.

Resulta necesario que esta estrategia ya probada en Chile en materia de lavado de activos se haga extensiva al modelo de prevención de delitos aludido en el art. $3^{\circ}$ in. $3^{\circ}$ Ley $\mathrm{N}^{\circ} 20.393$, estableciéndose que organismos públicos precisarán la forma específica como se implementarán sistemas de prevención de acuerdo con cada delito relevante. Sin perjuicio de ello, los preceptos infra-legales que concretarán la normativa penal general deberán cumplir con los requisitos establecidos para las leyes penales en blanco por parte del Tribunal Constitucional. Sólo de esta forma, el criminal compliance podrá incorporarse al Derecho Penal, sin vulnerar los principios fundamentales que enmarcan su ejercicio. 
Polít. crim. Vol. 13, № 25 (Julio 2018) Art. 6, pp. 208-232.

[http://www.politicacriminal.cl/Vol_13/n_25/Vol13N25A6.pdf]

\section{Bibliografía}

ARTAZA VARELA, Osvaldo, La Empresa como Sujeto de Imputación de Responsabilidad Penal. Fundamentos y límites, Madrid: Marcial Pons Ediciones Jurídicas y Sociales, 2013.

ARTAZA VARELA, Osvaldo, "Sistemas de prevención de delitos o programas de cumplimiento. Breve descripción de las reglas técnicas de gestión del riesgo empresarial y su utilidad en sede jurídico penal", Polít. Crim., Vol. 8, N 16 (2013), pp. 544-573.

BECKEMPER, Katharina, "Nemo tenetur-Grundsatz im Steuerstrafrecht. Verwertbarkeit einer gescheiterten Selbstanzeige?", ZIS, N 5 (2012), pp. 221-227.

BEDECARRATZ SCHOLZ, Francisco Javier, Rechtsvergleichende Studien zur Strafbarkeit juristischer Personen. Eine Untersuchung ihrer Strafzurechnungsmerkmale in den Rechtsordnungen von Chile, Deutschland, England, Frankreich, Spanien und den Vereinigten Staaten, Baden-Baden: Nomos, 2016.

BLOY, Duncan; PARRY, Philip et. al. (eds.), Bloy and Parry's Principles of Criminal Law, $4^{a}$ edición, Londres: Routledge Cavendish, 2000.

BOCK, Dennis, “Compliance y deberes de vigilancia en la empresa”, en: KUHLEN, Lothar, MONTIEL, Juan Pablo, ORTÍZ DE URBINA GIMENO, Íñigo (Eds.), Compliance y teoría del Derecho Penal, Madrid: Marcial Pons, 2013, pp. 107-124.

BOFILL GENZSCH, Jorge, "Estructuras de imputación y prevención de delitos al interior de la persona jurídica", en: WILENMANN VON BERNATH, Javier (coord.), Gobiernos corporativos. Aspectos esenciales de las reformas a su regulación, Santiago: Legal Publishing Chile, 2011, pp. 175-195.

BÖSE, Martin, "Strafbarkeit juristischer Personen - Selbstverständlichkeit oder Paradigmenwechsel im Strafrecht”, ZStW, N 126 (2014), pp. 132-165.

COLLADO GONZÁLEZ, Rafael, Empresas criminales. Un análisis de los modelos legales de responsabilidad penal de las personas jurídicas implementados por Chile $y$ España, Santiago: Legal Publishing Chile, 2013.

CURY URZÚA, Enrique, Derecho Penal, Parte General, 10 $0^{a}$ edición, Santiago: Ediciones Universidad Católica de Chile, 2011.

CURY URZÚA, Enrique, La ley penal en blanco, Bogotá: Editorial Temis, 1998.

DEISTER, Jochen; GEIER, Anton, "Der UK Bribery Act 2010 und seine Auswirkungen auf deutsche Unternehmen”, Corporate Compliance Zeitschrift, fascículo $\mathrm{N}^{\circ} 1$ (2011), pp. 12-18. 
BEDECARRATZ, Francisco. "La indeterminación del criminal compliance y el principio de legalidad".

DEL ROSAL BLASCO, Bernardo, "Sobre los elementos estructurales de la responsabilidad penal de las personas jurídicas: reflexiones sobre las SSTS 154/2016 y 221/2016 y sobre la Circular núm. 1/2016 de la Fiscalía General del Estado”, Diario La Ley, $\mathrm{N}^{\circ} 8732$ (2016), pp. 1-13.

DEL ROSAL BLASCO, Bernardo, "La delimitación típica de los llamados hechos de conexión en el nuevo artículo 31 bis, $\mathrm{n}^{\circ}$ 1, del Código Penal", Cuadernos de Política Criminal, $\mathrm{N}^{\circ} 103$ (2011), pp. 41-94.

ENGELHART, Marc, Sanktionierung von Unternehmen und Compliance: Eine rechtsvergleichende Analyse des Straf- und Ordnungswidrigkeitenrechts in Deutschland und den USA, $2^{a}$ edición, Berlin: Duncker \& Humblot, 2012.

GARCÍA CAVERO, Percy, Criminal Compliance, Lima: Palestra Editores S.A.C., 2014.

GETH, Christopher, "Selbstbelastungsfreiheit im Unternehmensstrafrecht - Konflikt zwischen Moderne und Tradition aus Schweizer Perspektive”, ZStW, No 126 (2014), pp. 105-121.

GÓMEZ-JARA DÍEZ, Carlos, La culpabilidad penal de la empresa, Madrid: Marcial Pons Ediciones Jurídicas y Sociales, 2005.

GUTIÉRREZ PÉREZ, Elena, "Los compliance programs como eximente o atenuante de la responsabilidad penal de las personas jurídicas. La "eficacia e idoneidad" como principios rectores tras la reforma de 2015", Revista General de Derecho Penal, n²4 (2015), pp. 1-24.

HAUSCHKA, Christoph (Ed.), Corporate Compliance. Handbuch der Haftungsvermeidung im Unternehmen, $2^{\mathrm{a}}$ edicion, München: C.H. Beck, 2010.

HERNÁNDEZ BASUALTO, Héctor, “¿Derecho de las personas jurídicas a no autoincriminarse?", Revista de Derecho de la Pontificia Universidad Católica de Valparaíso, № 44 (2015), pp. 217-263.

HERNÁNDEZ BASUALTO, Héctor, "Desafíos de la ley de responsabilidad penal de las personas jurídicas”, Revista de Estudios de la Justicia, № 16 (2012), pp. 75-98.

HERNÁNDEZ BASUALTO, Héctor, "La introducción de la responsabilidad penal de las personas jurídicas en Chile”, Polít. Crim., Vol. 5, Nº 9 (2010), pp. 207-236.

HUGGER, Heiner; RÖHRICH, Raimund, "Der neue UK Bribery Act und seine Geltung für deutsche Unternehmen”, Betriebs-Berater, año 2010, pp. 2643-2647.

JOHNSON, Timothy, "Sentencing Organizations after Booker", The Yale Law Journal, T. 116, N 3 (2006), pp. 632-666. 
Polít. crim. Vol. 13, № 25 (Julio 2018) Art. 6, pp. 208-232.

[http://www.politicacriminal.cl/Vol_13/n_25/Vol13N25A6.pdf]

KAPPEL, Jan; LAGODNY, Otto, "Der UK Bribery Act - Ein Strafgesetz erobert die Welt? -Ein kritischer Diskussionsanstoß-”, Strafverteidiger, T. 32, fascículo N ${ }^{\circ} 11$ (2012), pp. 695-701.

KUHLEN, Lothar, "Compliance y Derecho Penal en Alemania”, en: MIR PUIG, Santiago, CORCOY BIDASOLO, Mirentxu, GÓMEZ MARTÍN, Víctor (dirs.), Responsabilidad de la Empresa y Compliance. Programas de prevención, detección y reacción penal, Madrid: Edisofer S. L., 2014, pp. 89-125.

MATUS ACUÑA, Jean Pierre, "Sobre el valor de las certificaciones de adopción e implementación de modelos de prevención de delitos frente a la responsabilidad penal de las personas jurídicas", Revista Chilena de Derecho y Ciencias Penales, Vol. II, $\mathrm{N}^{\circ} 2$ (2013), pp. 11-22.

NANDA, Ved, "Corporate Criminal Liability in the United States: Is a New Approach Warranted?", en: PIETH, Mark; IVORY, Radha, Corporate Criminal Liability. Emergence, Convergence and Risk, Heidelberg: Springer, 2011, pp. 63-89.

NEIRA PENA, Ana María, "La efectividad de los criminal compliance programs como objeto de prueba en el proceso penal", Polit. Crim., Vol. 11, N²2 (2016), pp. 467520 .

NIETO MARTÍN, Adán, "Problemas fundamentales del cumplimiento normativo en el Derecho penal", en: KUHLEN, Lothar, MONTIEL, Juan Pablo, ORTÍZ DE URBINA GIMENO, Íñigo (Eds.), Compliance y teoría del Derecho Penal, Madrid: Marcial Pons, 2013, pp. 21-50.

NIETO MARTÍN, Adán, "Cosmetic Use and Lack of Precision in Compliance Programs: Any Solution?”, Eucrim, № 3 (2012), pp. 124-127.

NIETO MARTíN, Adán, La Responsabilidad Penal de las Personas Jurídicas: un Modelo Legislativo, Madrid: Iustel, 2008.

ORTIZ DE URBINA GIMENO, Íñigo, "Responsabilidad penal de las personas jurídicas: The American Way", en: MIR PUIG, Santiago, CORCOY BIDASOLO, Mirentxu, GÓMEZ MARTÍN, Víctor (dirs.), Responsabilidad de la Empresa y Compliance. Programas de prevención, detección y reacción penal, Madrid: Edisofer S. L., 2014, pp. 35-88.

PIÑA ROCHEFORT, Juan Ignacio, Modelos de Prevención de Delitos en la Empresa, Santiago: Legal Publishing Chile, 2012.

ROBLES PLANAS, Ricardo, "Strafe und juristische Person. Eine Kritik des Art. 31 bis des spanischen Strafgesetzbuches", ZIS, N 7 (2012), pp. 347-360.

ROTSCH, Thomas (ed.), Criminal Compliance: Handbuch, Baden-Baden: Nomos, 2015. 
BEDECARRATZ, Francisco. "La indeterminación del criminal compliance y el principio de legalidad".

ROTSCH, Thomas, "Compliance und Strafrecht - Fragen, Bedeutung, Perspektiven. Vorbemerkungen zu einer Theorie der sog. 'Criminal Compliance'”, ZStW, $\mathrm{N}^{\circ} 125$ (2013), pp. 481-498.

ROXIN, Claus, Strafrecht Allgemeiner Teil, T. 1, 4ª edición, München: C.H. Beck, 2006.

SCHNEIDER, Uwe, "Compliance als Aufgabe der Unternehmensleitung", Zeitschrift für Wirtschaftsrecht, año 2003, pp. 645-650.

SILVA SÁNCHEZ, Jesús-María, "Die strafrechtliche Haftung von juristischen Personen nach spanischem Strafrecht”, en: KEMPF, Eberhard; LÜDERSSEN, Klaus; VOLK, Klaus (Eds.), Unternehmensstrafrecht, Berlin: Walter de Gruyter, 2012, pp. 59-70.

STRAUCH, Mark, "Der Sarbanes-Oxley Act und die Entwicklungen im US-Aufsichtsrecht", Neue Zeitschrift für Gesellschaftsrecht, fascículo N²0 (2003), pp. 952-956.

TOSO MILOS, Ángela, "La regulación de prevención del lavado de activos relativa al momento en que se debe conocer a los clientes. Reflexiones derivadas de su aplicación por el banco emisor de un crédito documentario", Revista Ius et Praxis, año 22, $\mathrm{N}^{\circ} 2$ (2016), pp. 19-52.

TOSO MILOS, Ángela, "Blanqueo de capitales su prevención en el ordenamiento jurídico chileno", Revista Chilena de Derecho, Vol. 35 N 3 (2008), pp. 405-437.

VAN WEEZEL, Alex, "Contra la responsabilidad penal de las personas jurídicas", Polit. Crim., Vol. 5, N 9 (2010), pp. 114-142.

WITTIG, Petra, Wirtschaftsstrafrecht, $3^{a}$ edición, München: C.H. Beck, 2014. 